\title{
Influence of temperature on the biaxial strength of cemented carbides with different microstructures
}

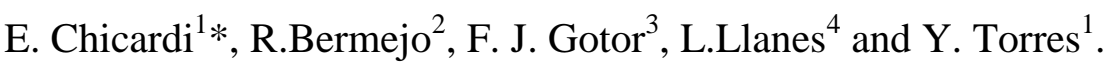

${ }^{1}$ Departamento de Ingeniería y Ciencia de los Materiales y del Transporte, Escuela Politécnica de Sevilla (EPS). Universidad de Sevilla (US), Virgen de Africa 7, 41011 Sevilla, Spain.

2 Institut fuer Struktur- und Funktionskeramik, Montanuniversitaet Leoben, 8700 Leoben, Austria.

${ }^{3}$ Instituto de Ciencia de Materiales de Sevilla (US-CSIC), 41092 Sevilla, Spain.

4 Departament de Ciència dels Materials i Enginyeria Metallúrgica, Universitat Politècnica de Catalunya, 08028 Barcelona, Spain.

*E-mail: echicardi@us.es

Abstract. The effect of the temperature on the mechanical strength of WC-Co cemented carbides with different microstructures (grain size and binder content) was evaluated. Biaxial flexural tests were performed on three cemented carbide grades at $600^{\circ} \mathrm{C}$ using the ball-on-three-balls (B3B) method. Results were interpreted by Weibull statistics and compared to biaxial strength results at room temperature. A detailed fractographic analysis, supported by Linear Elastic Fracture Mechanics, was performed to differentiate the nature and size of critical defects and the mechanism responsible for the fracture. A significant decrease in the mechanical strength (around 30\%) was observed at $600^{\circ} \mathrm{C}$ for all grades of cemented carbides. This fact was ascribed to the change in the critical flaw population from sub-surface (at room temperature) to surface defects, associated with the selective oxidation of Co. Additionally, an estimation of the fracture toughness at $600^{\circ} \mathrm{C}$ was attempted for the three cemented carbides, based upon the $\mathrm{B} 3 \mathrm{~B}$ strength results, the corresponding number of the tested specimens fragments and the macroscopic area of the B3B fracture surfaces. The fracture toughness was not 
affected by the temperature, at least up to $600^{\circ} \mathrm{C}$. In addition, the good agreement with the Single Edge Notch Beam toughness data suggests the possibility of employing this approach for fracture toughness evaluation of brittle materials under different testing conditions.

Keywords: Cemented carbides; temperature; Weibull statistics, biaxial flexural strength; Ball on three Balls.

\section{Introduction}

WC-Co cemented carbides, also known as hard metals, are ceramic-metal composite materials with exceptional combination of hardness, strength, toughness, elastic modulus and wear resistance [1, 2]. Such remarkable mechanical properties result from the synergic effect of their constituent phases, i.e., a hard brittle tungsten carbide (WC) and a soft ductile metallic phase (Co) [3]. The microstructure of WC-Co cemented carbides are usually faceted WC grains, with rectangular or triangular morphology, embedded in a Co-based alloy acting as binder [4]. Other minor secondary carbides ( $\mathrm{TiC}, \mathrm{TaC}, \mathrm{NbC}, \mathrm{Mo}_{2} \mathrm{C}$, etc.) and metallic elements ( $\mathrm{Ni}, \mathrm{V}, \mathrm{Cr}$, etc.) are added to modulate the microstructure, the chemical stability and the mechanical behavior of these materials [5-7]. Moreover, the use of fine WC particles is also another option to improve their mechanical properties [8].

Cemented carbides are widely used as cutting tools, among other industrial applications. As the cutting speed increases, the operating conditions become more demanding in terms of thermo-mechanical stresses that often endanger their reliability in service. In this regard, cemented carbides exhibit low oxidation resistance and damage tolerance at the high temperatures that can be reached on the tool/chip interface 
while in service [1-4]. It has been reported that the formation of defects at high temperature as a result of oxidation and the growth of the pre-existing flaws are the main causes of the loss of stiffness, mechanical strength and fracture toughness during service [9-12]. These detrimental effects begin to be significant at temperatures above $600^{\circ} \mathrm{C}$ [13], and in the $800-900^{\circ} \mathrm{C}$ range, depending on the binder content, hard metals reach full oxidation [14]. Acchar et al. [8] found a large loss in mechanical strength from $600^{\circ} \mathrm{C}$ and Fantozzi et al. [15] reported that the Young's modulus and the mechanical strength decreased with temperature, which was particularly important beyond $500^{\circ} \mathrm{C}$. However, a small increase in fracture toughness has been reported between $600-700^{\circ} \mathrm{C}$ associated with elastic-plastic transition $[15,16]$, although this effect is only temporary since from $700^{\circ} \mathrm{C}-800^{\circ} \mathrm{C}$ the fracture toughness diminishes again because of oxidation [15]. Moreover, the mechanical behavior of cemented carbides at high temperature not only depends on the working atmosphere (oxygen partial pressure) and the exposure time, but also on the nature, content and particle size of the constituent phases $[9,14,17]$ as well as the inherent flaws associated with the manufacturing process, such as pores, ceramic agglomerates, coarse ceramic particles, eta phases, etc. $[18,19]$.

At room temperature, cemented carbides show defect controlling fracture strength, which is associated with the size of the largest (or critical) defect in the material. The type of intrinsic defects in these materials ranges from pores to non-metallic inclusions, as well as abnormally large carbides or binderless carbide agglomerates, among other microstructural heterogeneities [20]. This can differ from specimen to specimen (or component to component) $[18,19]$. Therefore, strength cannot be described uniquely by a single number, but as a distribution function (related to the defect size distribution), where a probability of failure can be defined as the probability that fracture occurs at a 
stress equal to or lower than a given value, according to Weibull statistics [21, 22]. The probability of failure increases with the magnitude of the load (i.e. $\sigma$ ) and the size of the specimens (i.e. $V$ ). The size effect on strength is the most prominent consequence of the statistical behavior of strength in brittle materials, i.e., large specimens have higher probability of failure than smaller specimens under the same load applied.

In a previous work, the strength distribution of three cemented carbide grades with different microstructure was evaluated and compared under uniaxial (four-point bend, 4PB) and biaxial (ball-on-three-balls, B3B) bending at room temperature [23]. Characteristic strengths ranging from $2200 \mathrm{MPa}$ to $\sim 3000 \mathrm{MPa}$ were measured under 4PB, while higher values between $\sim 3300 \mathrm{MPa}$ and $\sim 4200 \mathrm{MPa}$ were obtained under B3B. This could be explained according to the size effect on strength in brittle materials, as predicted by the Weibull theory; extrapolation of the 4PB results for effective surface showed good agreement with the B3B experimental values. A higher Weibull modulus was measured in the WC-Co grade with pronounced R-curve under both $4 \mathrm{~PB}$ and $\mathrm{B} 3 \mathrm{~B}$, associated with the subcritical growth of initial defects. The question arises, whether a similar behavior is to be expected at elevated temperatures for the three grades.

The aim of this work was to evaluate the influence of temperature on the strength distribution of WC-Co cemented carbides with different microstructures, i.e., grain size and binder mean free path. Biaxial flexural tests were performed at $600^{\circ} \mathrm{C}$ using the B3B method and the results were compared to those at room temperature. A detailed fractographic analysis was performed to interpret the mechanism responsible for the fracture. Additionally, the fracture toughness of the tested cemented carbides was 
estimated based upon the strength data, the corresponding number of fragments of the tested specimens, and the macroscopic area of the fracture surfaces.

\section{Experimental}

\subsection{Materials}

Three WC-Co cemented carbide, named as $16 \mathrm{~F}, 16 \mathrm{M}$ and $27 \mathrm{C}$, according to a previous published work [3] and with different composition and/or microstructural parameters, were studied. In table 1, the mass percentage of cobalt, the WC average particle size, the binder mean free path and the Vickers hardness of the three different cemented carbides are shown, as characterized in previous work [24].

\subsection{Evaluation of the mechanical strength}

The mechanical strength of $16 \mathrm{~F}, 16 \mathrm{M}$ and $27 \mathrm{C}$ cemented carbides was evaluated by biaxial flexural tests using the B3B method $[25,26]$. This method is widely used for brittle materials (e.g. glasses, ceramics) [27-29], and has also been applied to cemented carbides [23, 30, 31], and even metal alloys [32], due to some advantages compared to the most common standardized tests, such as 3-point and 4-point bending. Specifically, the main advantages include ease preparation of test samples, high tolerance for some out of flatness of the disc and/or misalignment, much lower friction than in the other common tests, possibility of using small test specimens (even with irregular shape and closer to the real workpiece geometry), absence of tensile loaded edges, among others $[23,25,27,28,33]$. The main disadvantage of the B3B method is that the load is concentrated in a very small location of the sample and, thus, larger critical defects may not be sampled during the tests. 
Four alumina balls ( $3 \mathrm{~mm}$ of diameter) were used for the tests; three balls placed on the top and the fourth ball centered under the disc specimen. This geometric arrangement during loading guarantees a well-defined three-point contact. With this configuration, a biaxial tensile stress state at the midpoint of the disc surface opposite the loading ball (down surface) is generated during loading, which is used for the biaxial strength evaluation. More details about the test and a schematic representation can be found elsewhere $[23,33]$.

At least ten discs (13 $\mathrm{mm}$ of diameter and $0.7-1.3 \mathrm{~mm}$ of thickness) of each cemented carbide grade were tested. The surfaces were carefully ground and polished (final step with suspension diamond powder of $3 \mu \mathrm{m}$ ) to prevent surface damage and ensure the same surface quality in all specimens. The B3B tests were carried out by an electromechanical universal testing machine (Model 5505, Instron Ltd.) in ambient air, under load control at a rate of $100 \mathrm{~N} / \mathrm{s}$, coupled to a split furnace (Energon S.L) with refractory Molybdenum clamps (m.p. $=2623{ }^{\circ} \mathrm{C}$ ). The assembly of the device and disc was initially made at room temperature. Then, a $10 \mathrm{~N}$ pre-load was applied in order to guarantee the contact between the four balls and the disc during the heating step. The temperature was increased up to $600{ }^{\circ} \mathrm{C}$ ( $2 \mathrm{~h}$ were necessary to reach the temperature), always controlling and holding the imposed $10 \mathrm{~N}$ pre-load.

In the $\mathrm{B} 3 \mathrm{~B}$ test, the fracture load, $F$ (in $\mathrm{N}$ ), is used to calculate the maximum biaxial flexural strength, $\sigma_{\max }$, according to the following equation [25]:

$$
\sigma_{\max }=f \cdot \frac{F}{t^{2}}
$$

where $t$ (in $\mathrm{mm}$ ) is the disc thickness and $f$ a non-dimensional factor, which depends on the specimen geometry and position of the balls, the Poisson's ratio of the material, and 
the special features of the load transfer from the clamps to the disc. In this work, the values of $f$ ranged between 1.1 and 1.5 as determined from the equation by Börger, Supancic and Danzer [25], due to the different specimen thicknesses.

The fracture strength was statistically analyzed as a function of stress, which was related to a certain failure probability, $P_{f}$, using a two-parameter Weibull distribution. Assuming an homogeneous crack-size frequency density function [34], the following failure probability function, $P_{\mathrm{f}}$, can be defined [22]:

$$
P_{\mathrm{f}}(\sigma, V)=1-\exp \left[-\frac{V}{V_{0}}\left(\frac{\sigma}{\sigma_{0}}\right)^{m}\right]
$$

where $\sigma_{0}$ and $m$ are the characteristic strength and the Weibull modulus, respectively. The Weibull modulus, $m$, describes the scatter of the strength data, and the characteristic strength, $\sigma_{0}$, is the stress at which, for specimens of volume $V=V_{0}$, the failure probability is: $P_{\mathrm{f}}\left(\sigma_{0}, V_{0}\right)=1-\exp (-1) \approx 63 \%$. The determination of the Weibull distribution was performed according to the standard EN 843-5 [35]. In addition, the 90\% confidence intervals $(\mathrm{CI})$ were calculated for $\sigma_{0}$ and $m$, which represent the range where the true Weibull parameters (i.e. from the parent distribution) can be found with a $90 \%$ probability and that reflect the influence of the sampling procedure. They were determined according to the standard EN 843-5 [35].

The fracture surfaces of the tested discs were analyzed by Scanning Electron Microscopy (SEM) using a Hitachi S-4800 SEM-Field Emission Gun microscope and the Image Analysis software Image-Pro Plus 6.2 (Media Cybernetics Inc., USA). These fractographic analyses allow the determination and evaluation of the nature and size of 
the flaws causing the failure, and (in many cases) the (micro)-mechanism that may has been responsible for the fracture. In addition, the $\mathrm{WC}, \mathrm{Co}$ and $\mathrm{O}$ contents in the WC-Co cemented carbides were measured using an energy dispersive X-ray spectrometry (XEDS) detector coupled to the SEM microscope.

Finally, the measurements of the total area of the fracture surface, $S_{f}$, and the number of disc fragments associated with the fracture process, $N_{i}$, was carried out on a representative number of discs for each grade of cemented carbides using a Nikon Epiphot optical microscope coupled with a Jenoptik Progres C3 camera and the analysis software Image-Pro Plus 6.2.

\section{Results and discussion}

\subsection{Influence of temperature on the biaxial strength}

Fig. 1 shows the probability of failure versus the corresponding failure stress (Weibull plots) for the three commercial cemented carbides grades (16F, 16M and 27C) at room temperature $(\mathrm{RT})$ and $600^{\circ} \mathrm{C}$. The calculated $\sigma_{0}$ and $m$ values are presented in table 2, together with the corresponding 90\% CI. A detrimental effect of temperature on the mechanical strength of the three cemented carbides is evidenced in Fig. 1 (see characteristic values in table 2). The decrease of approx. $30 \%$ in strength at $600^{\circ} \mathrm{C}$ compared to RT may be mainly attributed to oxidation phenomena, as was directly observed at first sight on the surface of the discs after testing. As reported in the literature, the formation of oxidation products begins to be appreciable at $600^{\circ} \mathrm{C}$ [10]. In fact, previous works have shown a significant reduction of the mechanical strength of cemented carbides only after $10 \mathrm{~min}$ at $700^{\circ} \mathrm{C} \mathrm{[36].} \mathrm{Therefore,} \mathrm{it} \mathrm{is} \mathrm{not} \mathrm{surprising} \mathrm{that} \mathrm{an}$ 
oxidation process was associated with the testing procedure, since the samples were heated during $2 \mathrm{~h}$ to reach the testing temperature of $600^{\circ} \mathrm{C}$.

In addition to the loss of mechanical strength at $600^{\circ} \mathrm{C}$, an apparent increase of the Weibull modulus, $m$, was observed for the $16 \mathrm{~F}$ and $16 \mathrm{M}$ grades (the mean value of $m$ increasing from 8 to 10 , and 7 to 13 , for the two grades respectively). A higher $m$ may be associated with the subcritical growth of preexisting processing flaws, thus yielding a higher amount of defects of similar (larger) size. Another possibility might be the appearance of new flaws with a more homogeneous size distribution and location. In the case of grade $27 \mathrm{C}$, it seemed not to be an influence of the temperature on the Weibull modulus ( $m=10$ at RT versus $m=9$ at $600^{\circ} \mathrm{C}$ ). It is worthy pointing out that the $90 \% \mathrm{CI}$ for $m$ do overlap for the three WC-Co grades. In order to reinforce the hypothesis mentioned above for $16 \mathrm{~F}$ and $16 \mathrm{M}$ materials on the change of flaw distributions with temperature, more experiments would be required that may narrow the $90 \% \mathrm{CI}$, and thus reveal statistically significance differences in $m$. This aspect will be discussed in more detail in the following section, supported by fractographic considerations.

The effect of the microstructure on the mechanical strength of the cemented carbides is illustrated in Fig. $2 \mathrm{a}$ and $2 \mathrm{~b}$ at $\mathrm{RT}$ and at $600^{\circ} \mathrm{C}$, respectively. It can be observed how the influence of the microstructure on the probability of failure of the specimens was different for both evaluated temperatures. At RT and lower mechanical strength values, corresponding to larger inherent flaws (Fig. 2a), all three grades seem to have same behavior. In addition, a deviation from the expected Weibull behavior was observed in the $16 \mathrm{M}$ and $27 \mathrm{C}$ grades. In these two grades, the obtained curves using 2parameter Weibull distribution do not fit the strength data; there seems to be an apparent "threshold stress", at approx. $2800 \mathrm{MPa}$, below which the material does not fail. However, for smaller inherent flaws (higher mechanical strength values in Fig. 2a), the 
curves of probability of failure tend to separate, showing an important influence of the microstructure of the different cemented carbides. At $600^{\circ} \mathrm{C}$, the probability of failure curves are practically parallel for the three grades of cemented carbides studied in the full range of mechanical strength values, suggesting again an important influence of the microstructure (e.g. associated with the different $K_{\text {Ic }}$ measured for the different grades) and a more homogeneous flaw size distribution in comparison with the corresponding at RT. The latter might be related to oxidation effects at the surfaces, yielding a surface critical flaw distribution, in contrast to the sub-surface (or in some cases, volume) defects reported at RT, as will be shown in the following section.

\subsection{Characterization of the fracture surfaces}

Fig. 3 shows the SEM micrographs (secondary electrons) of the fracture surfaces and the characteristic critical defects for the three cemented carbide grades $(16 \mathrm{~F}, 6 \mathrm{M}$ and $27 \mathrm{C}$ ) tested at $600^{\circ} \mathrm{C}$ under biaxial bending. The low-magnification images (Figs. $3 \mathrm{a}, 3 \mathrm{c}$ and $3 \mathrm{e}$ ) allowed the observation of the typical macroscopic lines, radial marks or ridges, with a "fanlike pattern" emanating from the origin of the fracture (critical flaw) that was located at the surface of the disc specimen subjected to the maximum stress. Figs. $3 \mathrm{~b}, 3 \mathrm{~d}$ and $3 \mathrm{f}$, at a higher magnification, corresponding to the regions marked with squares in Figs. 3a, 3c and 3e, show these critical flaws (delimited by arrows), in which a dark contrast was always detected. This fact suggests the presence of carbides agglomerates and/or oxidation products formed near to the cemented carbide surface as responsible for the fracture during the biaxial tests at $600^{\circ} \mathrm{C}$.

Table 3 shows the experimental values for the size of the critical flaws $\left(2 a_{\mathrm{c}}\right)$ at $600^{\circ} \mathrm{C}$ measured from the SEM images. It is necessary to comment on the impossibility 
of evaluating the size of the critical flaws at RT due to the high number of broken pieces generated that impeded their detection. The size of the critical flaws, $a_{\mathrm{c}}$, at RT (table 3 ) was then estimated in the framework of the Linear Elastic Fracture Mechanics (LEFM) according to the following equation [37]:

$$
a_{c}=\frac{1}{\pi} \cdot\left(\frac{K_{I c}}{Y \cdot \sigma_{0}}\right)^{2}
$$

where $\sigma_{0}$ is the characteristic strength as determined in this work (see Table 2), and $K_{\text {Ic }}$ is the fracture toughness as determined in a previous work by the single edge notched bend (SENB) method [24]. $Y$ is a geometric factor that depends on the geometry and location of the flaw as well as on the loading configuration. For typical flaws underneath the tensile surface (i.e. volume flaws), $Y$ can be approximated by $2 / \pi$. However, for flaws reaching out the surface (as it is the case of the critical defects observed at $\left.600^{\circ} \mathrm{C}\right), Y$ may be approximated by $\sim(2 / \pi) \cdot 2^{1 / 2}$, thus being a factor $\sqrt{2}$ more critical than sub-surface flaws [24].

The defect size values estimated at RT were of the same order as those observed experimentally after 4-point bending tests [24]. Interestingly, these values were also similar in size to those observed at $600^{\circ} \mathrm{C}$ (see table 3). This fairly good agreement suggests that there are no significant differences in size for the flaws responsible for the fracture at both studied temperatures. However, the nature of the failure-controlling defect appears to be different at both temperatures. While it has been shown that the flaws at RT are sub-surface (volume) defects associated with the manufacturing process (pores, coarse WC and carbides agglomerates [11]), a detailed fractographic examination revealed that the flaws determining rupture at $600^{\circ} \mathrm{C}$ were localized at the surface and may be associated with the oxidation phenomena. 
Based upon the size of the critical flaws found at $600{ }^{\circ} \mathrm{C}$, an estimation of $K_{\mathrm{Ic}}$ was attempted using LEFM. When considering a geometric factor of $Y=2 / \pi$, as for subsurface (volume) flaws, lower $K_{\text {Ic }}$ values were estimated (see table 3). However, if considering the critical flaws as observed with fractography, i.e. near surface flaws, an upper bound for $K_{\text {Ic }}$ may be calculated (taken $Y=(2 / \pi) \cdot 2^{1 / 2}$ ), which is in the order of the $K_{\text {Ic }}$ measured by SENB at RT. Therefore, the fracture toughness seems to be not affected by temperature, at least up to $600^{\circ} \mathrm{C}$ in agreement with a previous published work by Johannessson and Warren [38].

\subsection{Micromechanisms of fracture at elevated temperatures}

Fig. 4 shows details of the micromechanisms responsible for the fracture in the cemented carbides during the biaxial tests at $\mathrm{RT}$ and $600^{\circ} \mathrm{C}$. The increase in the $\mathrm{WC}$ size from $16 \mathrm{~F}$ to $16 \mathrm{M}$ and finally to $27 \mathrm{C}$ was clearly observed. The three WC-Co show a transgranular fracture, suggesting an optimal bonding interaction between both WC and Co phases. Especially clear was the presence of cleavage (marked with continuous arrows in Fig. 4). This micromechanism is characteristic of brittle materials and is more likely when the glide of the dislocations is restricted (there is no movement of dislocations) [39]. In these cases, the fracture occurs along well-defined crystallographic planes - usually the (001) basal plane of the WC hexagonal structure -. A change of orientation from grain to grain is observed, steps are formed to accommodate these disorientations. The brittle transgranular fracture occurs without appreciable plastic deformation and in the direction perpendicular to the applied mechanical stress. Also, within the same WC can appear so-called river patterns (marked as dotted arrows in Fig. 4) $[40,41]$. On the other hand, the presence of dimples associated with ductile fracture is lower. The marked presence of cleavage can be explained by the intrinsic fragility of these materials and the high energy stored during the biaxial flexural tests. 
The fracture surfaces corresponding to the specimens tested at $600^{\circ} \mathrm{C}$ (Fig. 4) had a higher microporosity. This was the result of the release of some volatile tungsten oxide compounds (usually $\mathrm{WO}_{3}$ ) and $\mathrm{CO} / \mathrm{CO}_{2}$, products formed by the hard metal oxidation $[42,43]$. In these SEM images, a binder phase with a pseudo-granular aspect was clearly visible. To gain new insights into the nature of this new binder phase, XEDS_SEM elemental mappings were carried out. Fig. 5 illustrates the results obtained for the $27 \mathrm{C}$ cemented carbide tested at $600^{\circ} \mathrm{C}$. This figure shows that a non-negligible amount of oxygen was present in the specimen after testing. Moreover, the oxygen was associated not only with $\mathrm{W}$, but also with Co, showing the $\mathrm{O}$ and Co mappings an outstanding similar elemental distribution. Therefore, this new phase was composed of Co or mixed Co-W oxidation products [10].

Although it has been reported that the oxidation resistance of cemented carbides is improved by increasing the Co content [9], it has recently been demonstrated that this improvement is actually due to the presence of a higher amount of dense $\mathrm{CoWO}_{4}$ within the oxide scale (more protective than $\mathrm{WO}_{3}$ ), which reduces porosity [44]. Besides, it has also been shown that during the early oxidation stage of $\mathrm{WC}-\mathrm{Co}$ at intermediate temperatures, such as in the present work, the selective oxidation of Co takes place first [45]. At this stage, the Co phase is completely oxidized, while the WC phase only does it partly within a thin surface layer. The elemental XEDS mappings shown in Fig. 5 are in close agreement with these reported results. Therefore, the formation of oxidation products (new oxide phases) in the surface, with brittle characteristics that replace the ductile binder phase, might play a role in the degradation of the mechanical strength at higher temperatures, due to the critical flaws are now (at $600^{\circ} \mathrm{C}$ ) localized in the surface, in contrast to the subsurface critical flaws existing at RT. This aspect can be also corroborated attending to the elemental XEDS mapping carried out, in this case, on a 
polished cross section of the $27 \mathrm{C}$ cemented carbide tested at $600^{\circ} \mathrm{C}$ (Fig. 6). There, it is possible detecting a narrow oxidized layer (less than $1 \mu \mathrm{m}$ ) in the cemented carbide surface.

\subsection{Relationship between number of pieces and the biaxial flexural strength}

Yanaba and Hayasi [46] indicated that a relationship exists between the elastic energy accumulated during the breaking process, the number of broken pieces associated with the fracture test $\left(N_{\mathrm{i}}\right)$, the mechanical strength $\left(\sigma_{0}\right)$ and the fracture toughness $\left(K_{\mathrm{Ic}}\right)$. These two last mechanical properties are also related to the total fracture surface area $\left(S_{\mathrm{f}}\right)$ by the following equation (4):

$$
\sigma_{\mathrm{R}}=\varnothing \cdot K_{\mathrm{Ic}} \cdot S_{\mathrm{f}}^{1 / 2}
$$

where $\varnothing$ is a shape factor depending on both the size and shape of the fracture source and the size of the test piece.

Fig. 7 displays characteristic images of the cemented carbide specimens with the number of broken pieces obtained after the B3B tests. Fig. 8 shows the relationship between the mechanical strength, $\sigma_{0}$, and the number of broken pieces, $N_{i}$, regardless of the temperature. The number of broken pieces for the specimens tested at $600^{\circ} \mathrm{C}$ was always lower than at RT, suggesting a lower energy absorbed before fracture and/or the presence of larger and more homogeneous defects. Moreover, if $N_{i}$ and the temperature of the test are fixed, a direct relationship between $\sigma_{0}$ and $K_{I c}$ is obtained. It is necessary to comment the particular behavior observed in the $16 \mathrm{~F}$ cemented carbide tested at RT. Two populations of number of pieces were found. This mismatch could be easily consequence of the higher energy absorbed for $16 \mathrm{~F}$ at RT previously to fracture that 
caused a very high number of small pieces. In some cases, some of these small pieces were impossible to collect, causing an error in the number quantification. The image in Fig 7 for the $16 \mathrm{~F}$ cemented carbide tested at RT shows as it was impossible to completely restore the disc specimen.

By other hand, a direct relationship between $\sigma_{0}, N_{i}$ and $S_{\mathrm{f}}$ at $600^{\circ} \mathrm{C}$ was also found (see Table 2 and 4) and displayed in Fig. 9. Only the tested specimens that introduced less uncertainty in the determination of $S_{\mathrm{f}}$ were selected. The three fitted lines were imposed to pass through the origin $(\mathrm{x}=0$ and $\mathrm{y}=0)$ in order to obtain lines without $y$ intercept, according to equation (4). From the slopes of Fig. 9 and assuming the same shape factor, $\varnothing$, for the three cemented carbides, it was possible to determine a ratio between the fracture toughness values of the three cemented carbides. These ratios were compared in table 4 with those obtained from the values determined by LEFM at $600^{\circ} \mathrm{C}$ and by SENB method at RT. The ratios obtained by LEFM and SENB show a better agreement than when compared to those determined by the equation 4 . The differences observed in this case, greater when the $16 \mathrm{~F}$ grade is involved, are the consequence of the uncertainty to define and measure the real fracture surface area since the samples break into many pieces because of store high amount of energy before fracture.

\section{Conclusions}

The influence of the microstructure and the temperature on the mechanical strength of three commercial 16F, 16M and 27C cemented carbides (WC-Co) was determined using the ball-on-three-balls (B3B) biaxial flexural tests. For the three cemented carbides studied, a significant decrease in the mechanical strength (around $30 \%$ ) was observed at $600^{\circ} \mathrm{C}$, associated mainly with the change in the location of the 
critical defects due to the selective oxidation of the binder phase. In addition, the fracture toughness of the three cemented carbides was not affected by the temperature, at least up to $600^{\circ} \mathrm{C}$.

The viability of the $\mathrm{B} 3 \mathrm{~B}$ biaxial flexural test for testing WC-Co was demonstrated at elevated temperatures, enabling the observation of oxidation phenomena and their consequence on strength by revealing a new critical (surface) flaw population compared to sub-surface flaws found at room temperature.

In addition, a direct relationship between the numbers of broken fragments after B3B testing, the mechanical strength and the total fracture surface area was observed. This interesting protocol developed by Yanaba and Hayasaki [46] and corroborated here for the three cemented carbides studied, opens the possibility to generate diagrams for different brittle materials, connecting their fragment numbers after mechanical testing with their fracture toughness. Of special interest is the application of this procedure when the fracture toughness testing may become difficult.

\section{Acknowledgments}

This work was supported by the Andalusian government (Spain) under the excellence project no. P12-TEP-2622. Funding for this investigation was also partly supplied by the Spanish MINECO/FEDER under Grant No. MAT2015-70780-C4-3-P. The authors want to thank the technician J. Pinto and M. Sánchez for their assistance with mechanical testing and microstructural characterization. 


\section{References}

[1] Tarragó JM, Jiménez-Piqué E, Schneider L, Casellas D, Torres Y, Llanes L. FIB/FESEM experimental and analytical assessment of R-curve behavior of $\mathrm{WC}-\mathrm{Co}$ cemented carbides. Materials Science and Engineering: A. 2015;645:142-9.

[2] Mari D, Bolognini S, Feusier G, Viatte T, Benoit W. Experimental strategy to study the mechanical behaviour of hardmetals for cutting tools. International Journal of Refractory Metals \& Hard Materials. 1999;17:209-25.

[3] Llanes L, Torres Y, Anglada M. On the fatigue crack growth behavior of WC-Co cemented carbides: kinetics description, microstructural effects and fatigue sensitivity. Acta Materialia. 2002;50:2381-93.

[4] Lavergne O, Robaut F, Hodaj F, Allibert CH. Mechanism of solid-state dissolution of WC in Co-based solutions. Acta Materialia. 2002;50:1683-92.

[5] Juhani K, Pirso J, Viljus M, Letunovits S, Tarraste M. The Influence of Cr3C2 and VC as Alloying Additives on the Microstructure and Properties of Reactive Sintered WC-Co Cermets. Materials Science-Medziagotyra. 2012;18:79-83.

[6] Lee HR, Kim DJ, Hwang NM, Kim DY. Role of vanadium carbide additive during sintering of WC-Co: Mechanism of grain growth inhibition. Journal of the American Ceramic Society. 2003;86:152-4.

[7] Zhang L, Xie M-w, Cheng X, Nan Q, Wang Z, Feng Y-p. Micro characteristics of binder phases in WC-Co cemented carbides with $\mathrm{Cr}-\mathrm{V}$ and $\mathrm{Cr}-\mathrm{V}-\mathrm{RE}$ additives. International Journal of Refractory Metals \& Hard Materials. 2013;36:211-9.

[8] Acchar W, Gomes UU, Kaysser WA, Goring J. Strength Degradation of a Tungsten Carbide-Cobalt Composite at Elevated Temperatures. Materials Characterization. $1999 ; 43: 27-32$. 
[9] Basu SN, Sarin VK. Oxidation behavior of WC-Co. Materials Science and Engineering a-Structural Materials Properties Microstructure and Processing. 1996;209:206-12.

[10] Voitovich VB, Sverdel VV, Voitovich RF, Golovko EI. Oxidation of WC-Co, WC$\mathrm{Ni}$ and WC-Co-Ni hard metals in the temperature range 500-800 degrees C. Int J Refract Met Hard Mater. 1996;14:289-95.

[11] Arenas F, Ribas N, Brito J, Albornoz A, Cho SA. Examination of oxidation products in WC-Co hard metals. Bristol: Iop Publishing Ltd; 1998.

[12] Lee G. Oxidation Behavior of WC-Co Hardmetal. Joural of Korean Power Metallurgy Instit. 2004;11:111-7.

[13] Huang S, Xiong J, Guo Z, Wan W, Tang L, Zhong H, et al. Oxidation of WC-TiCTaC-Co hard materials at relatively low temperature. International Journal of Refractory Metals \& Hard Materials. 2015;48:134-40.

[14] Babutina TE, Uvarova IV. Effect of the conditions of oxidation of lump wastes of WC-Co(Ni) hard alloys on the dispersity of the oxidized mixtures. Powder Metallurgy and Metal Ceramics. 1997;36:107-10.

[15] Fantozzi G, Mohand H, Orange G. High temperature mechanical behaviour of WC6 wt.\% Co cemented carbide. Science of hard materials. 1986;20:699-712.

[16] Milman YV, Luyckx S, Goncharuck VA, Northrop JT. Results from bending tests on submicron and micron WC-Co grades at elevated temperatures. International Journal of Refractory Metals \& Hard Materials. 2002;20:71-9.

[17] Bhaumik SK, Balasubramaniam R, Upadhyaya GS, Vaidya ML. oxidation behavior of hard and binder phase modified WC-10Co cemented carbides. Journal of Materials Science Letters. 1992;11:1457-9. 
[18] Davidge RW. Mechanical Behaviour of Ceramics. Cambridge: Cambridge University Press; 1980.

[19] Danzer R. Ceramics: mechanical performance and lifetime prediction. Oxford: Pergamon Press; 1994.

[20] Fischmeister H. Development and Present Status of the Science and Technology of Hard Materials. In: R.K. Viswanadham DJRaJG, editor. Proc of ICSHM1 - 1st Int Conf on the Science of Hard Materials. New York: Plenum Press; 1981.p. 1-45.

[21] Danzer R. A general strength distribution function for brittle materials. J Eur Ceram Soc. 1992;10:461-72.

[22] Weibull W. A statistical distribution function of wide applicability. J Appl Mech. $1951 ; 18: 253$.

[23] Torres Y, Bermejo R, Gotor FJ, Chicardi E, Llanes L. Analysis on the mechanical strength of WC-Co cemented carbides under uniaxial and biaxial bending. Materials \& Design. 2014;55:851-6.

[24] Torres Y, Casellas D, Anglada M, Llanes L. Fracture toughness evaluation of hardmetals: influence of testing procedure. Int J Refract Met Hard Mater. 2001;19:2734.

[25] Börger A, Supancic P, Danzer R. The ball on three balls test for strength testing of brittle discs: Stress distribution in the disc. Journal of the European Ceramic Society. 2002;22:1425-36.

[26] Danzer R, Harrer W, Supancic P, Lube T, Wang Z, Börger A. The ball on three balls test-Strength and failure analysis of different materials. Journal of the European Ceramic Society. 2007;27:1481-5. 
[27] Bermejo R, Supancic P, Aldrian F, Danzer R. Experimental approach to assess the effect of metallization on the strength of functional ceramic components. Scripta Materialia. 2012;66:546-9.

[28] Bermejo R, Supancic P, Krautgasser C, Morrell R, Danzer R. Subcritical crack growth in Low Temperature Co-fired Ceramics under biaxial loading. Engineering Fracture Mechanics. 2013;100:108-21.

[29] Wagner R, Harrer W, Danzer R. Application of the Ball on Three Balls Test in the Development of a High Strength Partially Stabilised Zirconia Ceramic. Cfi-Ceramic Forum International. 2009;86:E50-E3.

[30] Chicardi E, Torres Y, Cordoba JM, Hvizdos P, Gotor FJ. Effect of tantalum content on the microstructure and mechanical behavior of cermets based on (TixTa1x)(C0.5N0.5) solid solutions. Materials \& Design. 2014;53:435-44.

[31] Chicardi E, Torres Y, Córdoba JM, Sayagués MJ, Rodríguez JA, Gotor FJ. Effect of sintering time on the microstructure and mechanical properties of $(\mathrm{Ti}, \mathrm{Ta})(\mathrm{C}, \mathrm{N})$-based cermets. International Journal of Refractory Metals and Hard Materials. 2013.

[32] Benavente-Martinez E, Devesa F, Amigo V. Mechanical characterization of Ti-Nb alloys by ball on three balls test. Revista De Metalurgia. 2010;46:19-25.

[33] Börger A, Supancic P, Danzer R. The ball on three balls test for strength testing of brittle discs: Part II: Analysis of possible errors in the strength determination. Journal of the European Ceramic Society. 2004;24:2917-28.

[34] Bermejo R, Danzer R. 2.09 - Mechanical Characterization of Ceramics: Designing with Brittle Materials A2 - Sarin, Vinod K. Comprehensive Hard Materials. Oxford: Elsevier; 2014. p. 285-98.

[35] EN 843-5. Advanced Technical Ceramics - Monolithic Ceramics - Mechanical Tests at Room Temperature - Part 5: Statistical Analysis. EN 843-51997. p. 40. 
[36] Casas B, Ramis X, Anglada M, Salla JM, Llanes L. Oxidation-induced strength degradation of WC-Co hardmetals. International Journal of Refractory Metals \& Hard Materials. 2001;19:303-9.

[37] Irwin GR. Fracture. In: Flügge S, editor. Handbuch der Physik. Berlin: SpringerVerlag; 1958. p. 551-89.

[38] Johannesson B, Warren R. Subcritical crack growth and plastic deformation in the fracture of hard metals. Materials Science and Engineering: A. 1988;105-106:353-61. [39] Sheikh S, M'Saoubi R, Flasar P, Schwind M, Persson T, Yang J, et al. Fracture toughness of cemented carbides: Testing method and microstructural effects. International Journal of Refractory Metals \& Hard Materials. 2015;49:153-60. [40] Wang G, Wang YT, Liu YH, Pan MX, Zhao DQ, Wang WH. Evolution of nanoscale morphology on fracture surface of brittle metallic glass. Applied Physics Letters. 2006;89:3.

[41] Riedle J, Gumbsch P, Fischmeister HF. Cleavage anisotropy in tungsten single crystals. Physical Review Letters. 1996;76:3594-7. [42] Garcia-Rosales C, Lopez-Ruiz P, Alvarez-Martin S, Calvo A, Ordas N, Koch F, et al. Oxidation behaviour of bulk W-Cr-Ti alloys prepared by mechanical alloying and HIPing. Fusion Engineering and Design. 2014;89:1611-6.

[43] Gu W-H, Jeong YS, Kim K, Kim J-C, Son S-H, Kim S. Thermal oxidation behavior of WC-Co hard metal machining tool tip scraps. Journal of Materials Processing Technology. 2012;212:1250-6.

[44] Aristizabal M, Sanchez JM, Rodriguez N, Ibarreta F, Martinez R. Comparison of the oxidation behaviour of $\mathrm{WC}-\mathrm{Co}$ and $\mathrm{WC}-\mathrm{Ni}-\mathrm{Co}-\mathrm{Cr}$ cemented carbides. Corrosion Science. 2011;53:2754-60. 
[45] Chen L, Yi D, Wang B, Liu H, Wu C. Mechanism of the early stages of oxidation of WC-Co cemented carbides. Corrosion Science. 2016;103:75-87.

[46] Yanaba Y, Hayashi K. Relation between fracture surface area of a flexural strength specimen and fracture toughness for WC-10mass \%Co cemented carbide and Si3N4 ceramics. Materials Science and Engineering a-Structural Materials Properties Microstructure and Processing. 1996;209:169-74.

[47] Danzer R. On the relationship between ceramic strength and the requirements for mechanical design. J Eur Ceram Soc. 2014;34. 
Table 1. Microstructural parameters and mechanical properties of the WC-Co cemented carbides studied.

\begin{tabular}{|c|c|c|c|c|}
\hline WC-Co grade & wt.\% Co & $\mathbf{d}_{\mathbf{w c}}(\mu \mathrm{m})$ & $\lambda_{\text {Co }}(\mu \mathrm{m})$ & HV30 $(\mathrm{GPa})$ \\
\hline $16 \mathrm{~F}$ & 10 & 0.50 & 0.25 & $15.5 \pm 2.5$ \\
\hline $16 \mathrm{M}$ & 10 & 1.06 & 0.30 & $14.0 \pm 2.6$ \\
\hline $27 \mathrm{C}$ & 16 & 1.66 & 0.76 & $11.2 \pm 0.8$ \\
\hline
\end{tabular}


Table 2. Influence of the microstructure and the temperature on the Weibull parameters $\left(\sigma_{0}\right.$ and $m$ ) for the three cemented carbides studied at room temperature (RT) [23] and at $600{ }^{\circ} \mathrm{C}$. The values shown in square brackets correspond to the $90 \%$ confidence intervals for the Weibull parameters.

\begin{tabular}{|c|c|c|c|c|}
\hline \multirow{2}{*}{ WC-Co grade } & \multicolumn{2}{|c|}{$\begin{array}{c}\text { Characteristic strength, } \boldsymbol{\sigma}_{\mathbf{0}}(\mathrm{MPa}) \\
{[90 \% \mathrm{CI}]}\end{array}$} & \multicolumn{2}{c|}{$\begin{array}{c}\text { Weibull modulus, } \boldsymbol{m} \\
{[90 \% \mathrm{CI}]}\end{array}$} \\
\cline { 2 - 5 } & $\mathbf{R T}$ & $\mathbf{6 0 0}{ }^{\circ} \mathbf{C}$ & $\mathbf{R T}$ & $\mathbf{6 0 0}{ }^{\circ} \mathrm{C}$ \\
\hline $16 \mathrm{~F}$ & $4208[3888-4567]$ & $2978[2787-3189]$ & $8[4-11]$ & $10[5-13]$ \\
\hline $16 \mathrm{M}$ & $3281[3012-3585]$ & $2258[2148-2377]$ & $7[4-10]$ & $13[7-17]$ \\
\hline $27 \mathrm{C}$ & $3341[3133-3571]$ & $2331[2156-2529]$ & $10[6-13]$ & $9[5-12]$ \\
\hline
\end{tabular}


Table 3. Critical flaw sizes, $2 a_{\mathrm{c}}$ : (i) estimated at RT and (ii) measured on fractured specimens at $600{ }^{\circ} \mathrm{C}$. Fracture toughness values, $K_{\text {Ic }}$, estimated at $600{ }^{\circ} \mathrm{C}$ using two different geometric factors: $Y=2 / \pi$ as for sub-surface flaws, and $Y=(2 / \pi) \cdot 2^{1 / 2}$ as for surface flaws contacting the surface.

\begin{tabular}{|c|c|c|c|c|c|}
\hline \multirow{2}{*}{$\begin{array}{l}\text { WC-Co } \\
\text { grade }\end{array}$} & \multicolumn{2}{|c|}{$\begin{array}{c}\text { Critical flaw sizes, } \boldsymbol{2}_{\mathbf{c}} \\
(\mu \mathrm{m})\end{array}$} & \multirow{2}{*}{$\begin{array}{l}\text { Measured } K_{\text {Ic }} \\
\text { by SENB at } \\
\text { RT }[24] \\
\left(\mathrm{MPam}^{1 / 2}\right)\end{array}$} & \multirow{2}{*}{$\begin{array}{l}\text { Estimated } K_{\text {Ic }} \\
\text { by LEFM at } \\
6^{600} \mathrm{C} \\
\left(\mathrm{MPam}^{1 / 2}\right)^{* *}\end{array}$} & \multirow{2}{*}{$\begin{array}{l}\text { Estimated } K_{\text {Ic }} \\
\text { by LEFM at } \\
\mathbf{6 0 0}^{\circ} \mathrm{C} \\
\left(\mathrm{MPam}^{1 / 2}\right)^{* * *}\end{array}$} \\
\hline & $\begin{array}{c}\text { @RT } \\
(\text { estimated)* }\end{array}$ & $\begin{array}{c}@ \mathbf{6 0 0}^{\circ} \mathbf{C} \\
\text { (measured) }\end{array}$ & & & \\
\hline $16 \mathrm{~F}$ & $6-9$ & $8-10$ & $9.2 \pm 0.6$ & $7.1 \pm 0.4$ & $9.9 \pm 0.4$ \\
\hline $16 \mathrm{M}$ & 14-19 & $19-22$ & $10.5 \pm$ & $8.1 \pm 0.4$ & $11.4 \pm 0.4$ \\
\hline $27 \mathrm{C}$ & $27-35$ & $30-32$ & $14.7 \pm 1.0$ & $10.1 \pm 1.1$ & $14.1 \pm 1.1$ \\
\hline \multicolumn{6}{|c|}{$\begin{array}{l}{ }^{*} 2 a_{\mathrm{c}} \text { values at RT estimated using LEFM from measured } \sigma_{0}[23], K_{\mathrm{Ic}}[24] \text { and } Y=(2 / \pi) \text { (as for sub-surface } \\
\text { flaws [47]) } \\
{ }^{* * *} K_{\mathrm{Ic}} \text { values } @ 600^{\circ} \mathrm{C} \text { estimated using LEFM from measured } 2 a_{\mathrm{c}}, \sigma_{0} \text { and } Y=(2 / \pi) \text { (as for sub-surface flaws } \\
[47]) \\
{ }^{* * * *} K_{\mathrm{Ic}} \text { values } @ 600^{\circ} \mathrm{C} \text { estimated using LEFM from measured } 2 a_{\mathrm{c}}, \sigma_{0} \text { and } Y=(2 / \pi) \cdot 2^{1 / 2} \text { (as for surface flaws } \\
\text { contacting the surface [47]) }\end{array}$} \\
\hline
\end{tabular}


Table 4. The total surface area $\left(S_{\mathrm{f}}\right)$ generated by the $\mathrm{B} 3 \mathrm{~B}$ tests at $600^{\circ} \mathrm{C}$ and the $K_{\text {Ic }}$ ratios obtained by $\mathrm{LEFM}$ at $600^{\circ} \mathrm{C}, \mathrm{SENB}$ at room temperature and using the slopes in Fig. 8 (equation (4)).

\begin{tabular}{|c|c|c|c|c|c|}
\hline \multirow{2}{*}{$\begin{array}{l}\text { WC-Co } \\
\text { grade }\end{array}$} & \multirow{2}{*}{$\begin{array}{c}S_{\mathrm{f}} \\
\left(\mathbf{m m}^{2}\right)\end{array}$} & \multicolumn{4}{|c|}{$K_{\text {Ic }}$ Ratios } \\
\hline & & & by LEFM & by SENB & by Eq. (4) \\
\hline $16 \mathrm{~F}$ & $7.9 \pm 0.4$ & 16F/16M & 0.87 & 0.88 & 1.08 \\
\hline $16 \mathrm{M}$ & $6.3 \pm 0.5$ & $16 \mathrm{~F} / 27 \mathrm{C}$ & 0.70 & 0.63 & 0.94 \\
\hline $27 \mathrm{C}$ & $5.4 \pm 0.2$ & $16 \mathrm{M} / 27 \mathrm{C}$ & 0.81 & 0.71 & 0.87 \\
\hline
\end{tabular}




\section{FIGURE CAPTIONS}

Figure 1. Weibull plots showing the influence of the temperature (room temperature $(\mathrm{RT})$ and $\left.600^{\circ} \mathrm{C}\right)$ on the mechanical strength of the three cemented carbide grades $(16 \mathrm{~F}$, $16 \mathrm{M}$ and 27C).

Figure 2. Weibull plots showing the influence of the microstructure on the mechanical strength of the three cemented carbide grades $(16 \mathrm{~F}, 16 \mathrm{M}$ and $27 \mathrm{C})$ at room temperature (RT) and $600^{\circ} \mathrm{C}$.

Figure 3. SEM micrograph of the fracture surface of the three cemented carbide grades after the $\mathrm{B} 3 \mathrm{~B}$ tests at $600^{\circ} \mathrm{C}$, showing the origin of the cracks (marked with squares) and the critical flaws (marked with arrows).

Figure 4. SEM images of the fracture surface of the three cemented carbide grades after the $\mathrm{B} 3 \mathrm{~B}$ tests at room temperature (RT) and $600^{\circ} \mathrm{C}$, showing the micromechanisms associated to the fracture: Dimples (dotted circles), transgranular fracture or cleavage (straight arrows) and river patterns (dotted arrows).

Figure 5. XEDS_SEM mappings of the fracture surface of the 27C cemented carbide after the B3B tests at room temperature (RT) and $600^{\circ} \mathrm{C}$.

Figure 6. XEDS_SEM mappings of the polished cross-section surface of the 27C cemented carbide after the $\mathrm{B} 3 \mathrm{~B}$ tests at room temperature $(\mathrm{RT})$ and $600^{\circ} \mathrm{C}$

Figure 7. Number of broken pieces obtained for the three cemented carbide grades $(16 \mathrm{~F}$, $16 \mathrm{M}$ and $27 \mathrm{C}$ ) after the $\mathrm{B} 3 \mathrm{~B}$ test at room temperature and $600^{\circ} \mathrm{C}$.

Figure 8. Relationship between the numbers of broken pieces after the B3B tests at room temperature (RT) and $600^{\circ} \mathrm{C}$ and the mechanical strength for the three cemented carbide grades (16F, 16M and 27C).

Figure 9. Relationship between the mechanical strength and the fracture surface area obtained after the $\mathrm{B} 3 \mathrm{~B}$ tests at $600^{\circ} \mathrm{C}$ for the three cemented carbide grades $(16 \mathrm{~F}, 16 \mathrm{M}$ and 27C). 

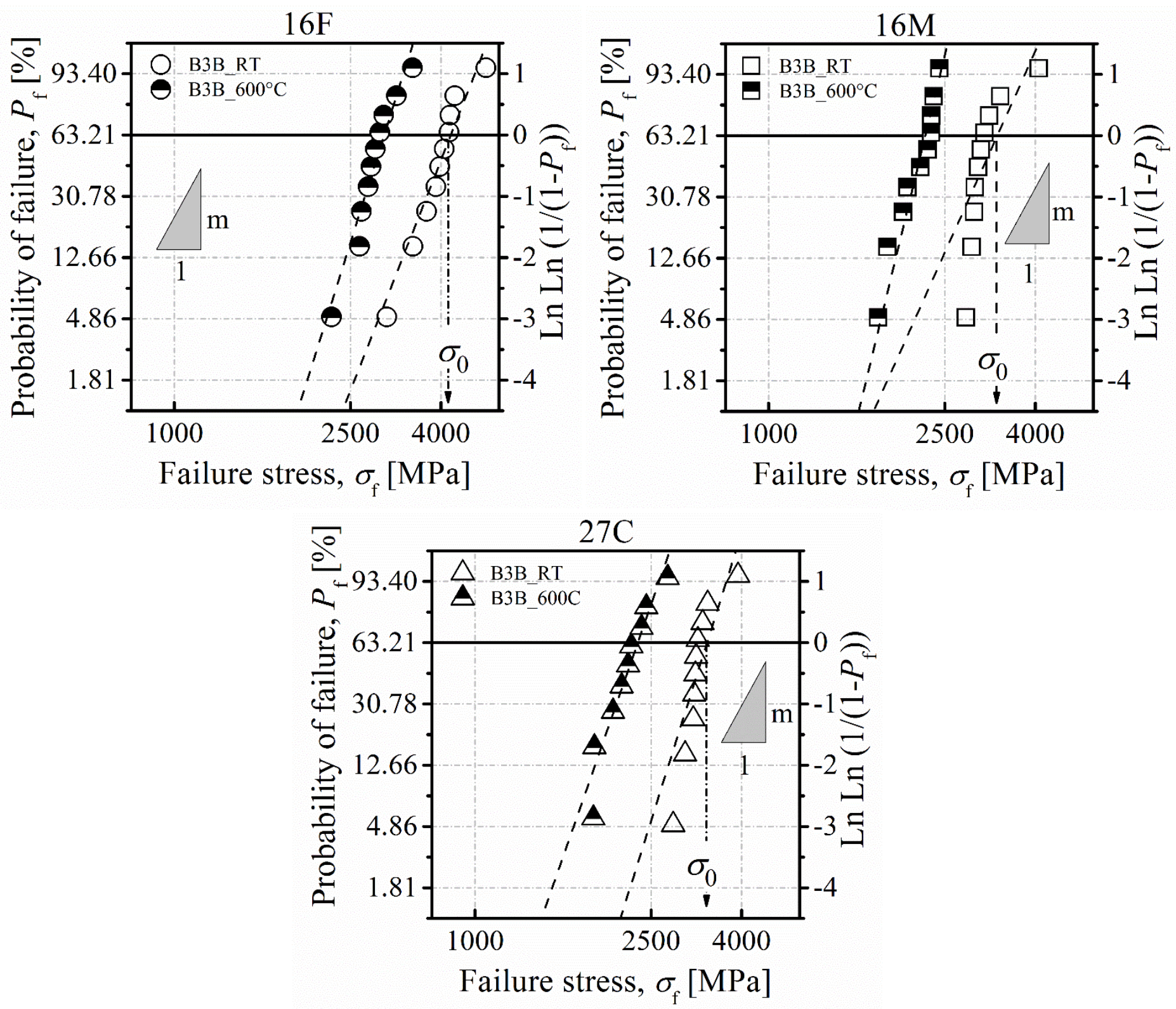

Figure 1 

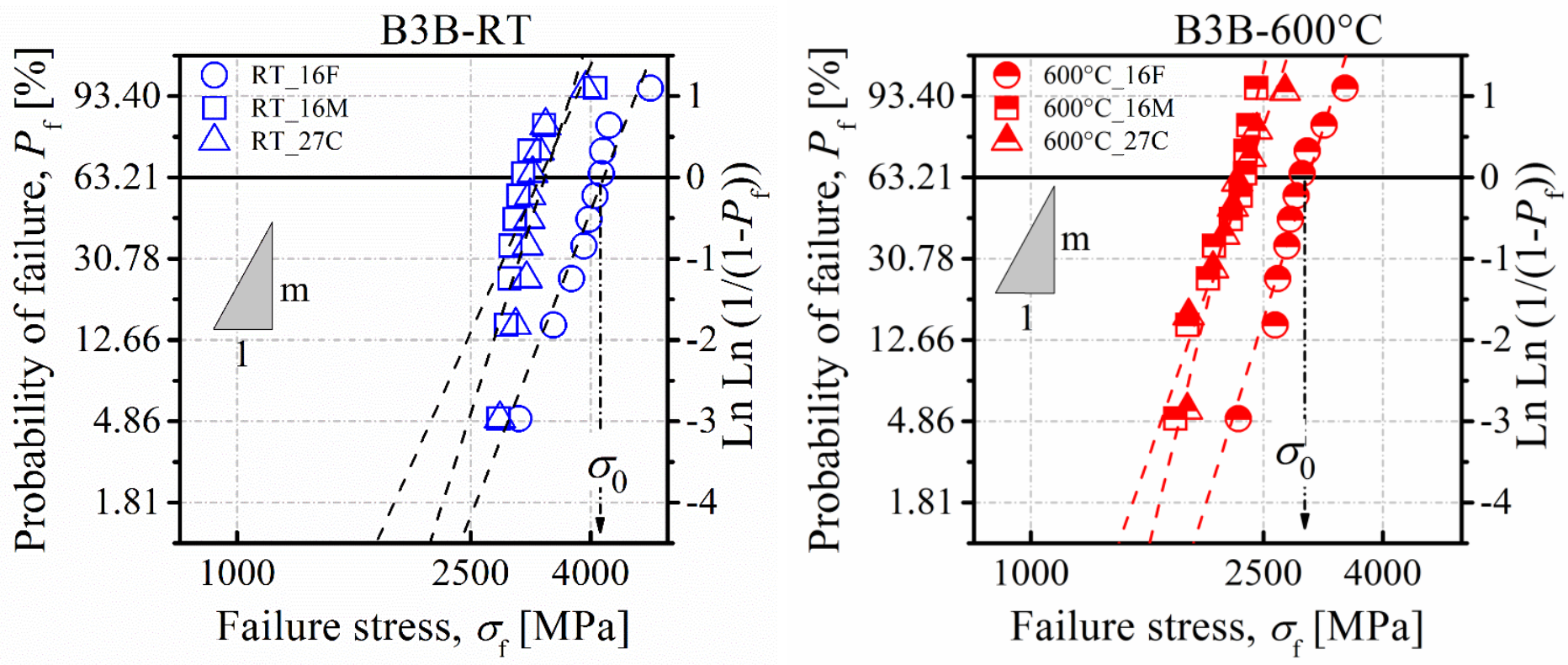

Figure 2 


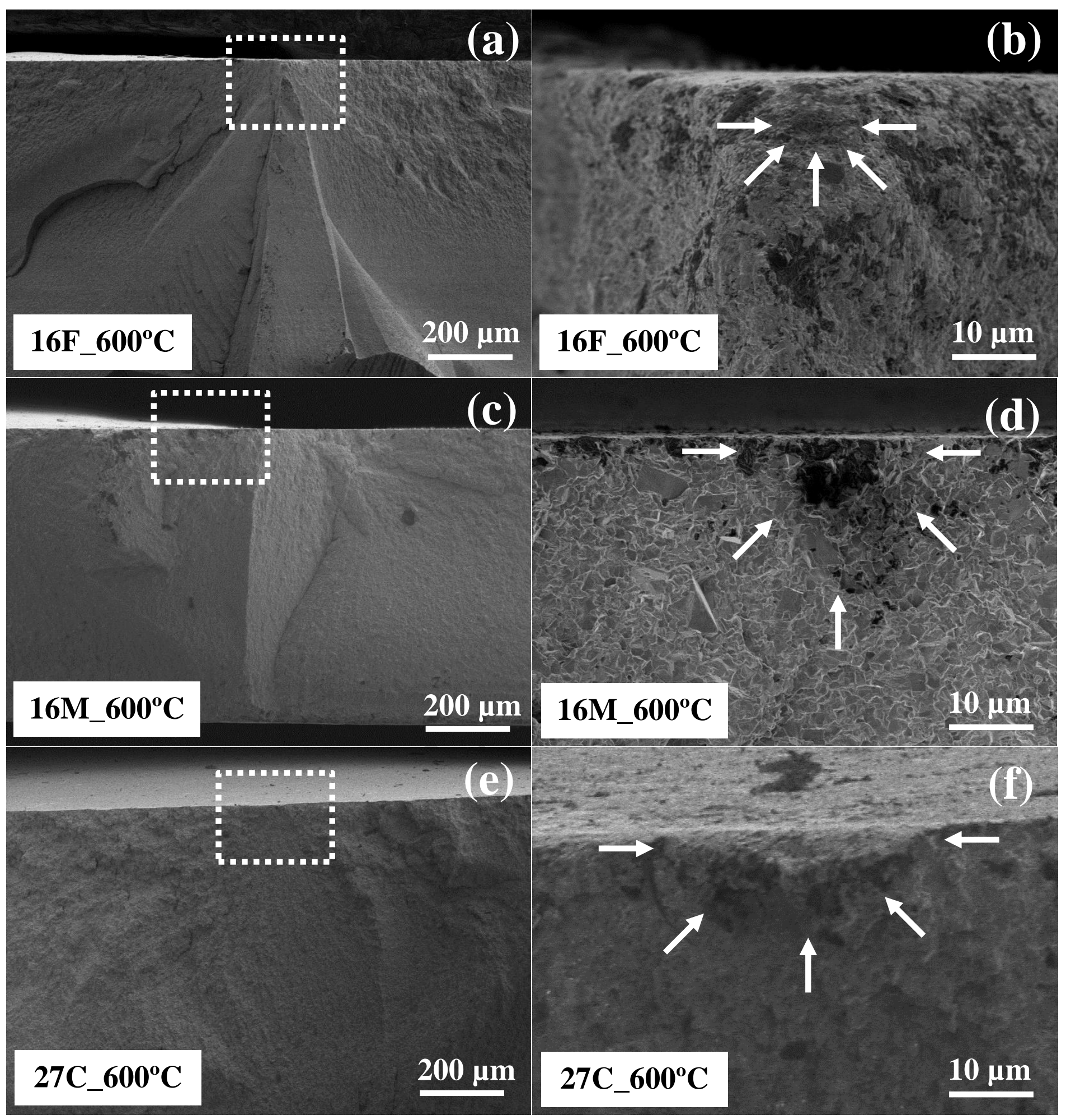



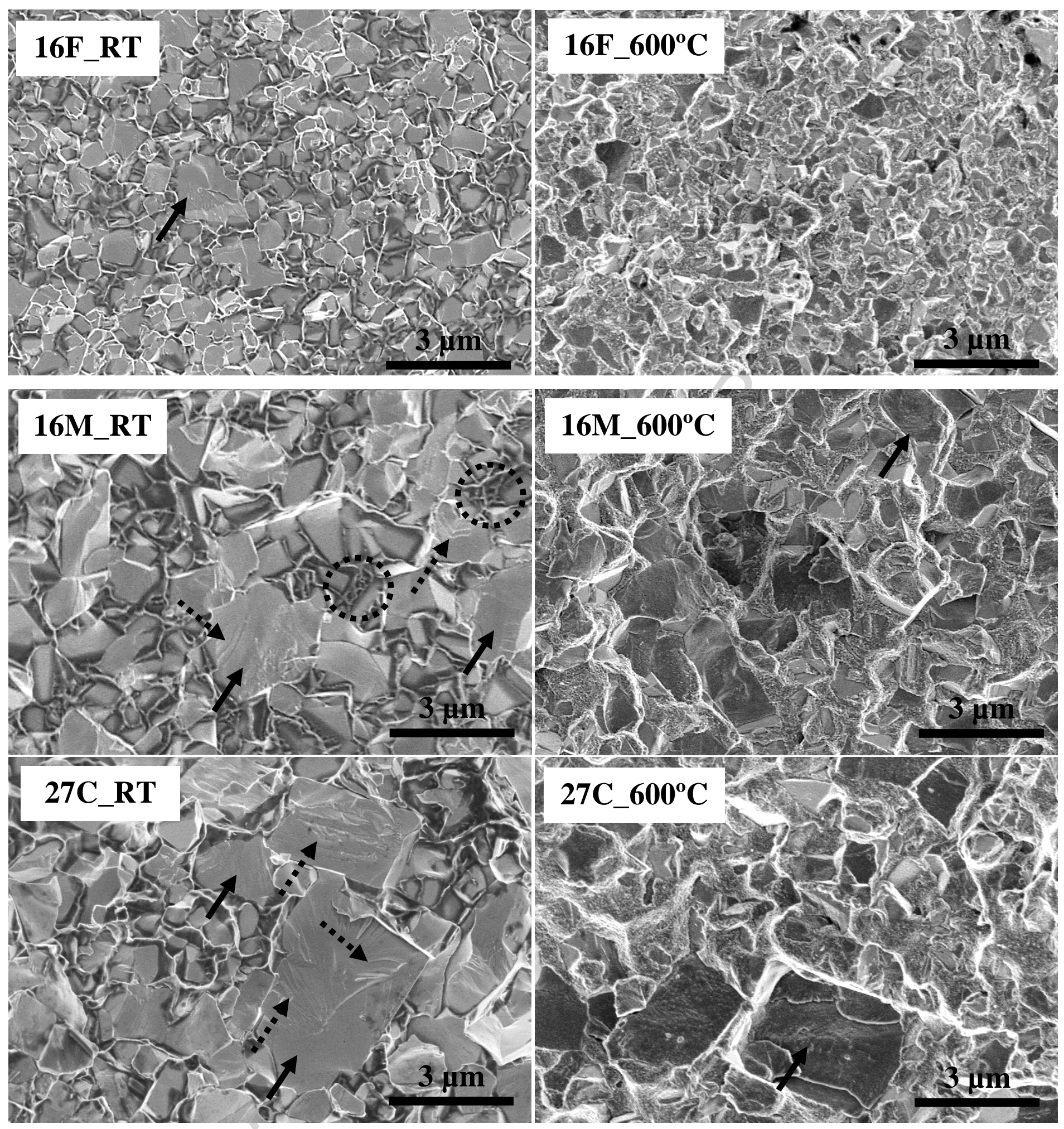

Figure 4 

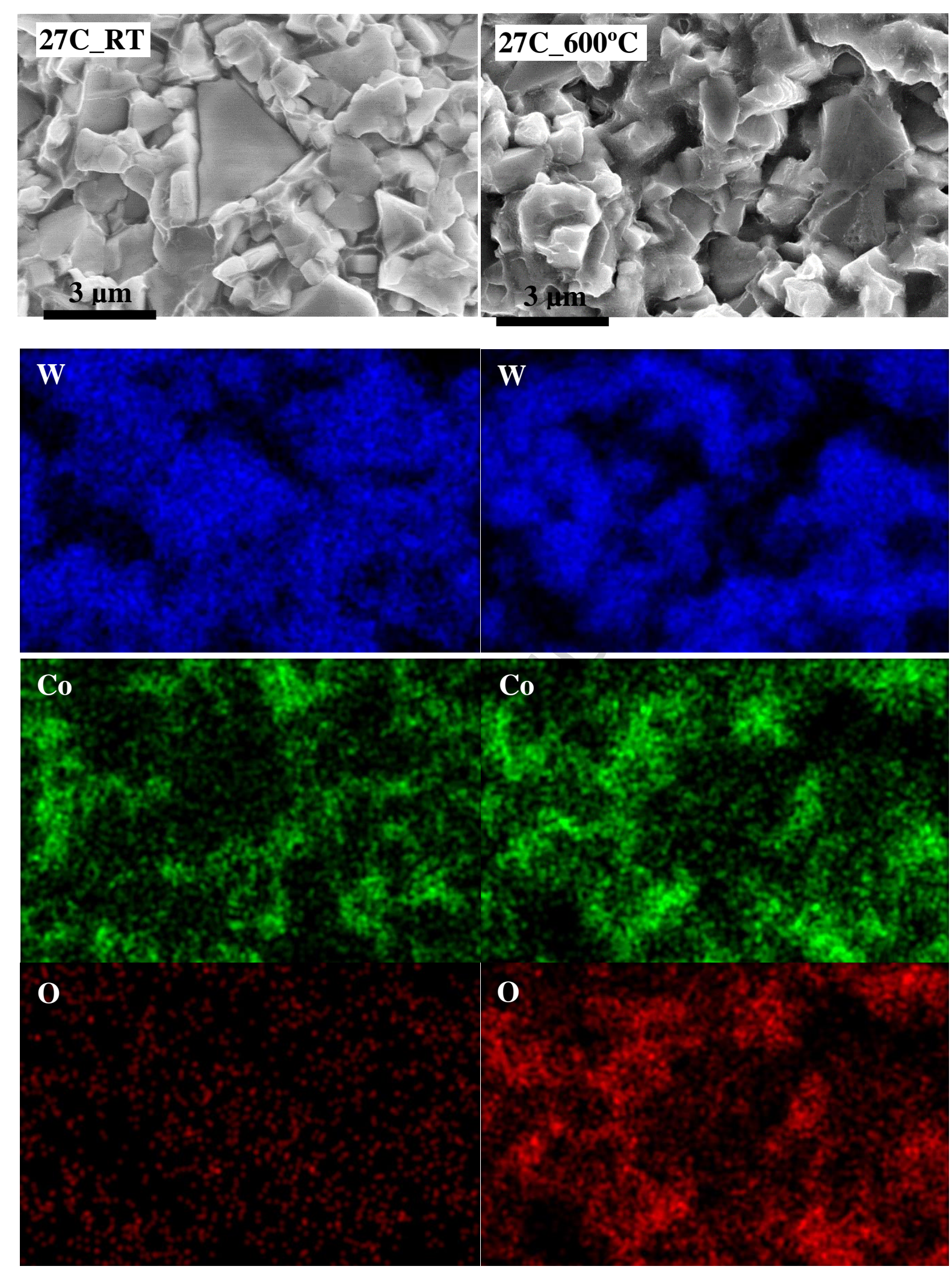

Figure 5 

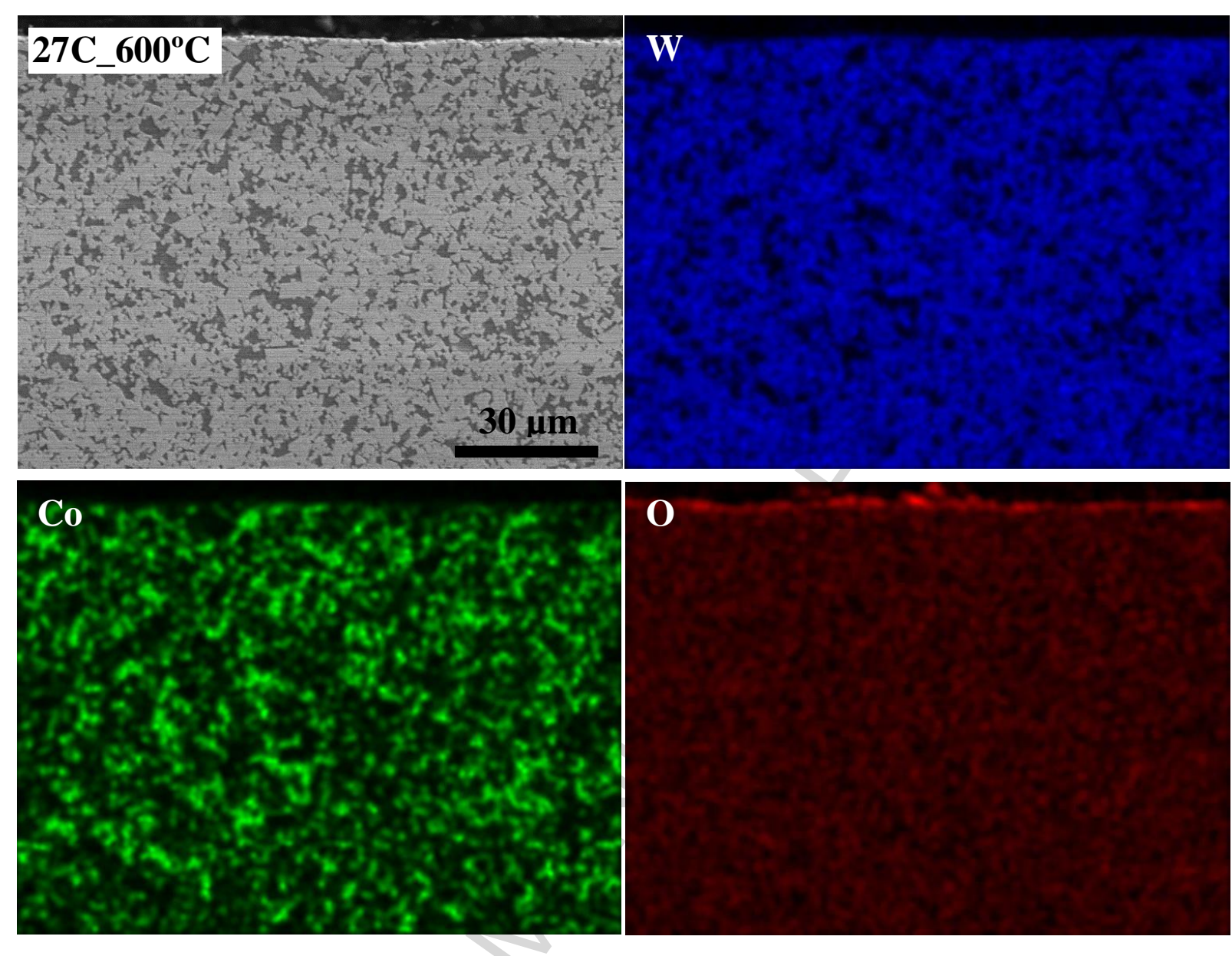

Figure 6 


\begin{tabular}{|c|c|c|c|c|}
\hline \multirow{2}{*}{ Specimen } & \multicolumn{2}{|c|}{ Room Temperature } & \multicolumn{2}{|c|}{ High temperature $\left(600^{\circ} \mathrm{C}\right)$} \\
\hline & Micrograph & Number of pieces & Micrograph & Number of pieces \\
\hline $16 \mathrm{~F}$ & & [7-18] & & {$[5-7]$} \\
\hline $16 \mathrm{M}$ & & {$[6-11]$} & & {$[2-4]$} \\
\hline $27 \mathrm{C}$ & & {$[3-8]$} & & {$[2-3]$} \\
\hline
\end{tabular}

Figure 7 
Figure 8

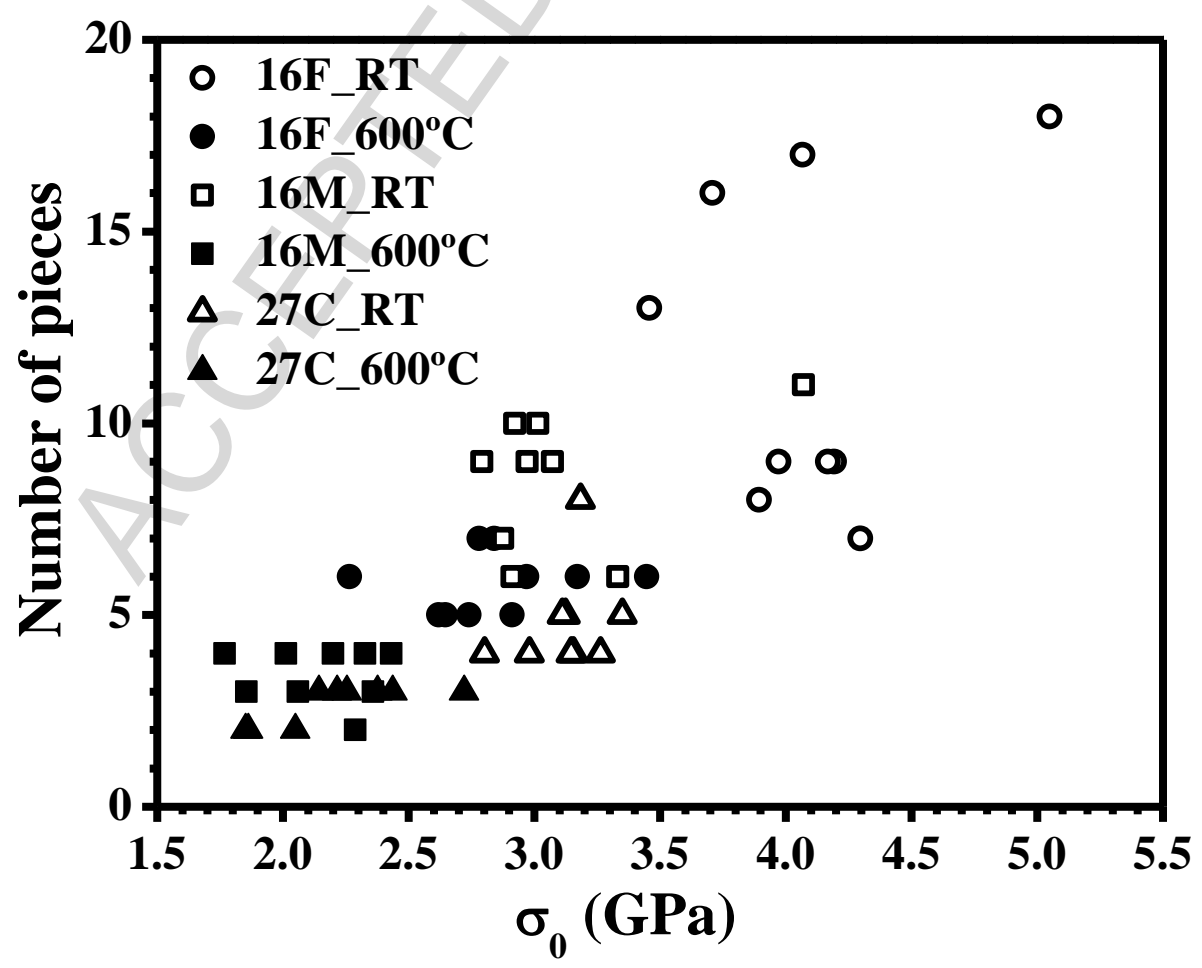




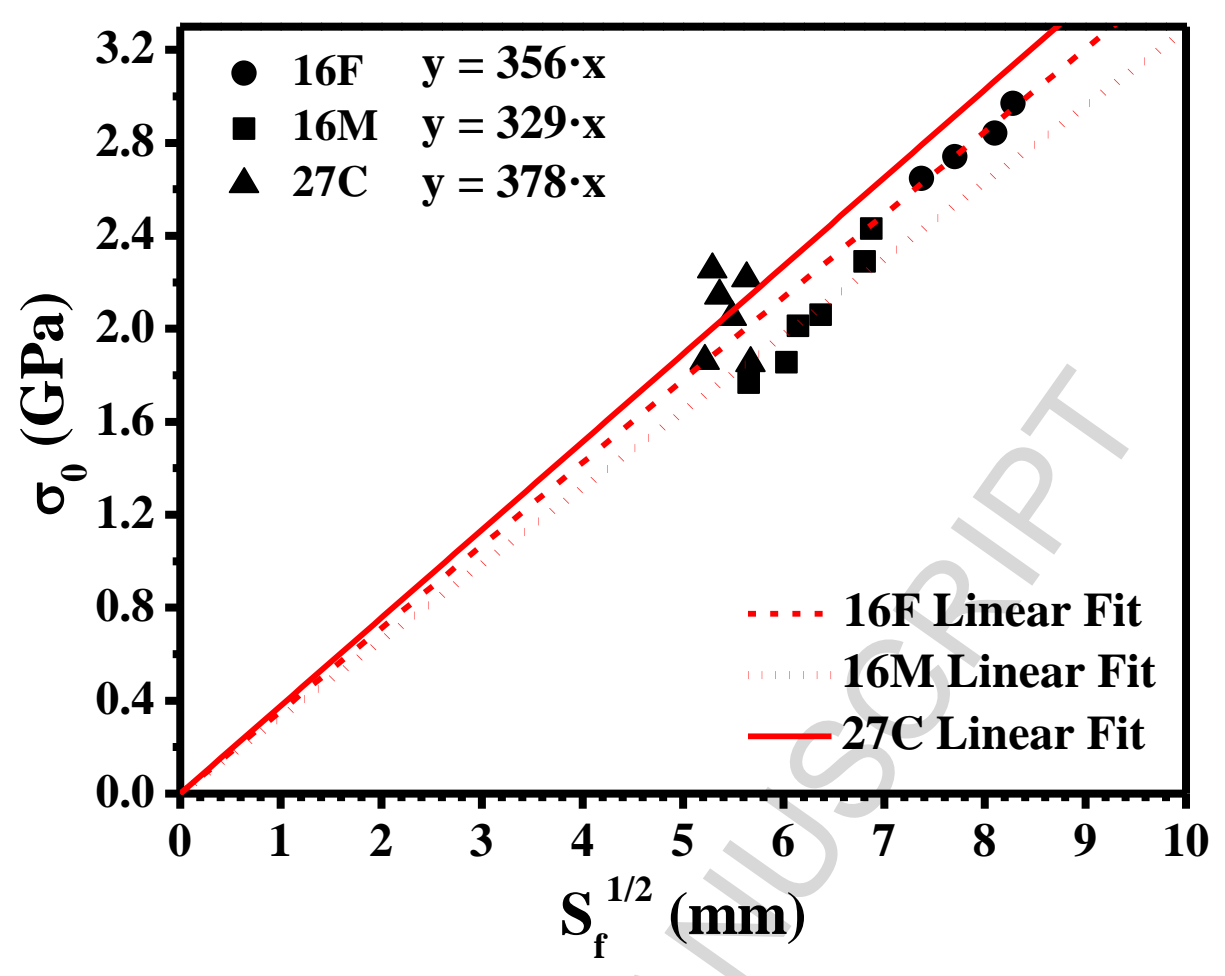

Figure 9 


\section{HIGHLIGHTS}

- The effect of the temperature on the WC-Co mechanical strength was determined.

- Biaxial flexural tests were performed at $600^{\circ} \mathrm{C}$ by the ball-on-three-balls method.

- A significant decrease in the mechanical strength $(\sim 30 \%)$ was observed at $600^{\circ} \mathrm{C}$.

- This fact was ascribed to the change of sub-surface to surface critical flaws.

- Additionally, the fracture toughness was not affected by the temperature. 